\title{
Application of Directed Orthometalation Toward the Synthesis of Aryl Siloxanes
}

\author{
W. Michael Seganish and Philip DeShong \\ Department of Chemistry and Biochemistry, University of Maryland \\ College Park, Maryland 20742
}

\section{SUPPORTING INFORMATION}

\section{Table of Contents}

Page

General Experimental

Synthesis of starting materials for metalation experiments

References

${ }^{1} \mathrm{H}$ NMR spectrum for 2-(triethoxysilyl) anisole

${ }^{1} \mathrm{H}$ NMR spectrum for 2-(triethoxysilyl) methoxymethoxybenzene

${ }^{1} \mathrm{H}$ NMR spectrum for 2-(triethoxysilyl) O- $N, N$-diethylcarbamoyl benzene

${ }^{1} \mathrm{H}$ NMR spectrum for 2-(triethoxysilyl) pivalanilide

${ }^{1} \mathrm{H}$ NMR spectrum for 2-(triethoxysilyl) $N$-tert-butoxycarbonyl aniline

${ }^{1} \mathrm{H}$ NMR spectrum for 2-diethlylcarbamoyl benzophenone

${ }^{1} \mathrm{H}$ NMR spectrum for $\mathrm{N}, \mathrm{N}$-diethyl-o-toluamide

${ }^{1} \mathrm{H}$ NMR spectrum for 2-methoxybiphenyl

${ }^{1} \mathrm{H}$ NMR spectrum for 4-methoxy-2-(N,N-diethyl-O-carbamoyl)biphenyl

${ }^{1} \mathrm{H}$ NMR spectrum for 2-methoxymethoxybiphenyl

${ }^{1} \mathrm{H}$ NMR spectrum for 2-pivalanilinebiphenyl

${ }^{1} \mathrm{H}$ NMR spectrum for 2-(N-tert-butoxycarbonyl)biphenyl

${ }^{1} \mathrm{H}$ NMR spectrum for 4-methoxy-2'-methoxybiphenyl

${ }^{1} \mathrm{H}$ NMR spectrum for methoxymethoxybenzne

${ }^{1} \mathrm{H}$ NMR spectrum for O-phenyldiethylcarbamate

${ }^{1} \mathrm{H}$ NMR spectrum for pivalaniline

${ }^{1} \mathrm{H}$ NMR spectrum for $N, N$-diethylbanzamide 


\section{General Experimental}

Thin-layer chromatography (TLC) was performed on $0.25 \mathrm{~mm}$ Merck silica gel coated plates treated with a UV-active binder with compounds being identified by one or more of the following methods: UV (254 nm), iodine, or vanillin/sulfuric acid charring. Flash chromatography was performed using thick walled columns and medium pressure silica gel (Whatman 200-425 mesh), with column length and diameter being determined by the method of Still. ${ }^{1}$

Melting points were taken in Kimax soft glass capillary tubes using a Thomas-Hoover Uni-Melt capillary melting point apparatus (Model 6406K) equipped with a calibrated thermometer.

IR band positions are reported in reciprocal centimeters $\left(\mathrm{cm}^{-1}\right)$ and relative intensities are listed as br (broad), s (strong), $\mathrm{m}$ (medium), or w (weak). Nuclear magnetic resonance $\left({ }^{1} \mathrm{H},{ }^{13} \mathrm{C}\right.$ NMR) spectra were recorded on a $400 \mathrm{MHz}$ spectrometer. Chemical shifts are reported in parts per million $(\delta)$ relative to tetramethylsilane (TMS). Coupling constants ( $J$ values) are reported in hertz $(\mathrm{Hz})$, and spin multiplicities are indicated by the following symbols: s (singlet), d (doublet), $\mathrm{t}$ (triplet), q (quartet), and $\mathrm{m}$ (multiplet).

Low resolution mass spectrometry (LRMS) and high resolution mass spectrometry (HRMS) data are reported in the form of $\mathrm{m} / \mathrm{z}$ (intensity relative to base peak $=100$ ). The matrix used for fast atom bombardment (FAB) was ethylene glycol.

Tetrahydrofuran and diethyl ether were distilled from sodium/benzophenone ketyl. Methylene chloride, and tetraethylorthosilicate, were distilled from calcium hydride. Dimethylformamide was distilled under reduced pressure from calcium sulfate. Ethanol was fractionally distilled from calcium chloride.

Palladium (II) acetate $\left(\mathrm{Pd}(\mathrm{OAc})_{2}\right)$ and tetrabutyl ammonium fluoride (1M solution in THF) were purchased from Acros and used as received. Triphenylphosphine was purchased from Aldrich and recrystallized from hexanes prior to use. All glassware used in these reactions was either oven dried at $120{ }^{\circ} \mathrm{C}$ for 12 hours or flame dried prior to use. All reactions were conducted under an atmosphere of argon.

All compounds were determined to be $>95 \%$ pure by ${ }^{1} \mathrm{H}$ NMR or GC analysis, unless otherwise noted. Previously reported compounds were characterized via ${ }^{1} \mathrm{H}$ and ${ }^{13} \mathrm{C}$ NMR and IR and compared to literature values. All new compounds were fully characterized using ${ }^{1} \mathrm{H}$ NMR, ${ }^{13} \mathrm{C}$ NMR, IR, low resolution and high resolution mass spectrometry. 


\section{Methoxymethoxybenzene (Table 1, entry 2)}

Phenol (1.88 g, $20.0 \mathrm{mmol})$ was dissolved in $15 \mathrm{~mL}$ of DMF. The solution was transferred via cannula to a suspension of $\mathrm{NaH}(0.768 \mathrm{~g}, 20.0 \mathrm{mmol})$ in $35 \mathrm{~mL}$ of DMF at $0{ }^{\circ} \mathrm{C}$ with significant evolution of gas. The reaction was allowed to warm to room temperature and was stirred for 15 min, then cooled to $0{ }^{\circ} \mathrm{C}$. Chloromethylmethyl ether $(3.04 \mathrm{~mL}, 40.0 \mathrm{mmol})$ was added and the reaction stirred for $5 \mathrm{~min}$ at $0{ }^{\circ} \mathrm{C}$, then $15 \mathrm{~min}$ at room temperature. The cloudy white solution was diluted with $50 \mathrm{~mL}$ of ether and poured into $50 \mathrm{~mL}$ of water. The organic layer was washed with $1 \mathrm{M} \mathrm{KOH}(50 \mathrm{~mL})$, water $(50 \mathrm{~mL})$, dried $\left(\mathrm{MgSO}_{4}\right)$, and concentrated in vacuo to yield a pale yellow oil which was purified via column chromatography $\left(19: 1\right.$ hexanes/EtOAc ,TLC $\left.\mathrm{R}_{\mathrm{f}}=0.32\right)$

to give the title compound as a colorless oil (97\%). The ${ }^{1} \mathrm{H}$ and ${ }^{13} \mathrm{C}$ NMR and IR match that reported by LeBel. ${ }^{2}$

\section{$O$-Phenyl diethylcarbamate (Table 1, entry 3)}

Diethyl carbamoyl chloride $(12.6 \mathrm{~mL}, 100 \mathrm{mmol})$ is added to a mixture of $\mathrm{K}_{2} \mathrm{CO}_{3}(13.8 \mathrm{~g}, 100$ $\mathrm{mmol})$ and phenol $(6.31 \mathrm{~g}, 67.0 \mathrm{mmol})$ in $135 \mathrm{~mL}$ of $\mathrm{MeCN}$. The reaction was refluxed for $3.5 \mathrm{~h}$ followed by the addition of $100 \mathrm{~mL}$ of water. The aqueous layer was extracted with ether (100 $\mathrm{mL} \times 3)$. The combined organic layers were washed with $100 \mathrm{~mL}$ of a $1 \mathrm{M} \mathrm{KOH}$ solution followed by $100 \mathrm{~mL}$ of water. The ethereal solution was then dried $\left(\mathrm{MgSO}_{4}\right)$ and concentrated in vacuo to produce a yellow oil. Kugelrohr distillation $\left(95^{\circ} \mathrm{C}, 0.3 \mathrm{~mm} \mathrm{Hg}\right)$ yielded a colorless oil $(92 \%) .{ }^{13} \mathrm{C}$ NMR $\left(\mathrm{CDCl}_{3}\right) \delta 13.4,14.2,41.9,42.2,121.7,125.0,129.2,151.6,154.2$. The ${ }^{1} \mathrm{H}$ NMR and IR match that reported by Snieckus. ${ }^{3}$

\section{Pivalanilide (Table 1, entry 4)}

Pivaloyl chloride $(26.3 \mathrm{~mL}, 214 \mathrm{mmol})$ was added slowly to a vigorously stirred biphasic solution of $\mathrm{Na}_{2} \mathrm{CO}_{3}(22.7 \mathrm{~g}, 214 \mathrm{mmol})$ in $100 \mathrm{~mL} \mathrm{H} \mathrm{H}_{2} \mathrm{O}$ and aniline $(9.78 \mathrm{~mL}, 107 \mathrm{mmol})$ in 100 $\mathrm{mL}$ of $\mathrm{CH}_{2} \mathrm{Cl}_{2}$. The reaction was refluxed for $1 \mathrm{~h}$ and diluted with $100 \mathrm{~mL}$ of $\mathrm{CH}_{2} \mathrm{Cl}_{2}$. The organic layer was extracted once with $100 \mathrm{~mL}$ of $1 \mathrm{M} \mathrm{NaOH}$, and twice with $100 \mathrm{~mL}$ of water, dried $\left(\mathrm{MgSO}_{4}\right)$ and concentrated to yield a slightly yellow crystalline solid. The solid was recrystallized from hexanes/EtOAc to produce white needles $(96 \%) \mathrm{mp} 133.1-133.5{ }^{\circ} \mathrm{C}$ (lit. 133.8-135.0 $\left.{ }^{\circ} \mathrm{C}\right)^{4} . \mathrm{IR}\left(\mathrm{CCl}_{4}\right) 3458(\mathrm{~s}), 3064$ (w), 3026 (w), 2964 (m), 2902 (w), 2871 (w), 1697 (s), 1597 (s), 1521 (s), 1435 (s), 1435 (s), 1314 (s), 1241 (m), 1148 (s). The ${ }^{1} \mathrm{H}$ and ${ }^{13} \mathrm{C}$ NMR match that reported by Lappert. ${ }^{4}$ 
tert-Butyl $N$-phenylcarbamate (Table 1 , entry 5)

Di-tert-butyl dicarbonate $(5.14 \mathrm{~g}, 23.5 \mathrm{mmol})$ was added in one portion to a stirred solution of aniline $(1.96 \mathrm{~mL}, 21.4 \mathrm{mmol})$ in $25 \mathrm{~mL}$ of THF. The reaction was heated to reflux for $3 \mathrm{~h}$. The solvent was removed in vacuo and the residue dissolved in $50 \mathrm{~mL}$ of EtOAc. The organic layer was washed twice with $1 \mathrm{M} \mathrm{HCl}(50 \mathrm{~mL})$, once with water $(50 \mathrm{~mL})$, dried $\left(\mathrm{MgSO}_{4}\right)$ and concentrated to yield a slightly yellow solid. Recrystallization $\left(\mathrm{CH}_{2} \mathrm{Cl}_{2}\right)$ yielded white flakes (97\%) mp 137.1-137.4 ${ }^{\circ} \mathrm{C}$ (lit. 136-137 $\left.{ }^{\circ} \mathrm{C}\right)^{5}$. IR ( $\left.\mathrm{CCl}_{4}\right) 3451$ (m), 3061 (w), 3029 (w), 3012 (w), 2978 (m), 2926 (w), 1735 (s), 1604 (m), 1521 (s), 1435 (s), 1366 (m), 1307 (m), 1162 (s). The ${ }^{1} \mathrm{H}$ and ${ }^{13} \mathrm{C}$ NMR match that reported by Smith. ${ }^{5}$

\section{$N, N$-Diethylbenzamide (Table 1 , entry 6 )}

To a stirred solution of benzoyl chloride $(2.48 \mathrm{~mL}, 21.3 \mathrm{mmol})$ in $25 \mathrm{~mL}$ of THF at $0{ }^{\circ} \mathrm{C}$ is added $6.62 \mathrm{~mL}(64.0 \mathrm{mmol})$ of diethylamine. The reaction is heated at reflux for two hours, followed by evaporation of the solvent. The residue is dissolved in $50 \mathrm{~mL}$ of EtOAc and washed three times with $1 \mathrm{M} \mathrm{HCl}(50 \mathrm{~mL})$, twice with saturated $\mathrm{NaHCO}_{3}(50 \mathrm{~mL})$, and once with water $(50 \mathrm{~mL})$. The organic layer was then dried $\left(\mathrm{MgSO}_{4}\right)$ and concentrated to a yellow oil. Kugelrohr distillation $\left(90{ }^{\circ} \mathrm{C}, 0.2 \mathrm{~mm} \mathrm{Hg}\right)$ yielded a colorless oil (96\%). The ${ }^{1} \mathrm{H}$ and ${ }^{13} \mathrm{C}$ NMR and IR match that reported by Burke. ${ }^{6}$

\section{REFERENCES}

(1) Still, W. C.; Kahn, M.; Mitra, A. J. Org. Chem. 1978, 43, 2923-2925.

(2) Agharahimi, M. R.; LeBel, N. A. J. Org. Chem. 1995, 60, 1856-1863.

(3) Sibi, M. P.; Chattopadhyay, S.; Dankwardt, J. W.; Snieckus, V. J. Am. Chem. Soc. 1985, 107, 6312-6315.

(4) Bezombes, J. P.; Hitchcock, P. B.; Lappert, M. F.; Merle, P. G. J. Chem. Soc., Dalton Trans. 2001, 816-821.

(5) Moraczewski, A. L.; Banaszynski, L. A.; From, A. M.; White, C. E.; Smith, B. D. J. Org. Chem. 1998, 63, 7258-7262.

(6) Hans, J. J.; Driver, R. W.; Burke, S. D. J. Org. Chem. 2000, 65, 2114-2121. 


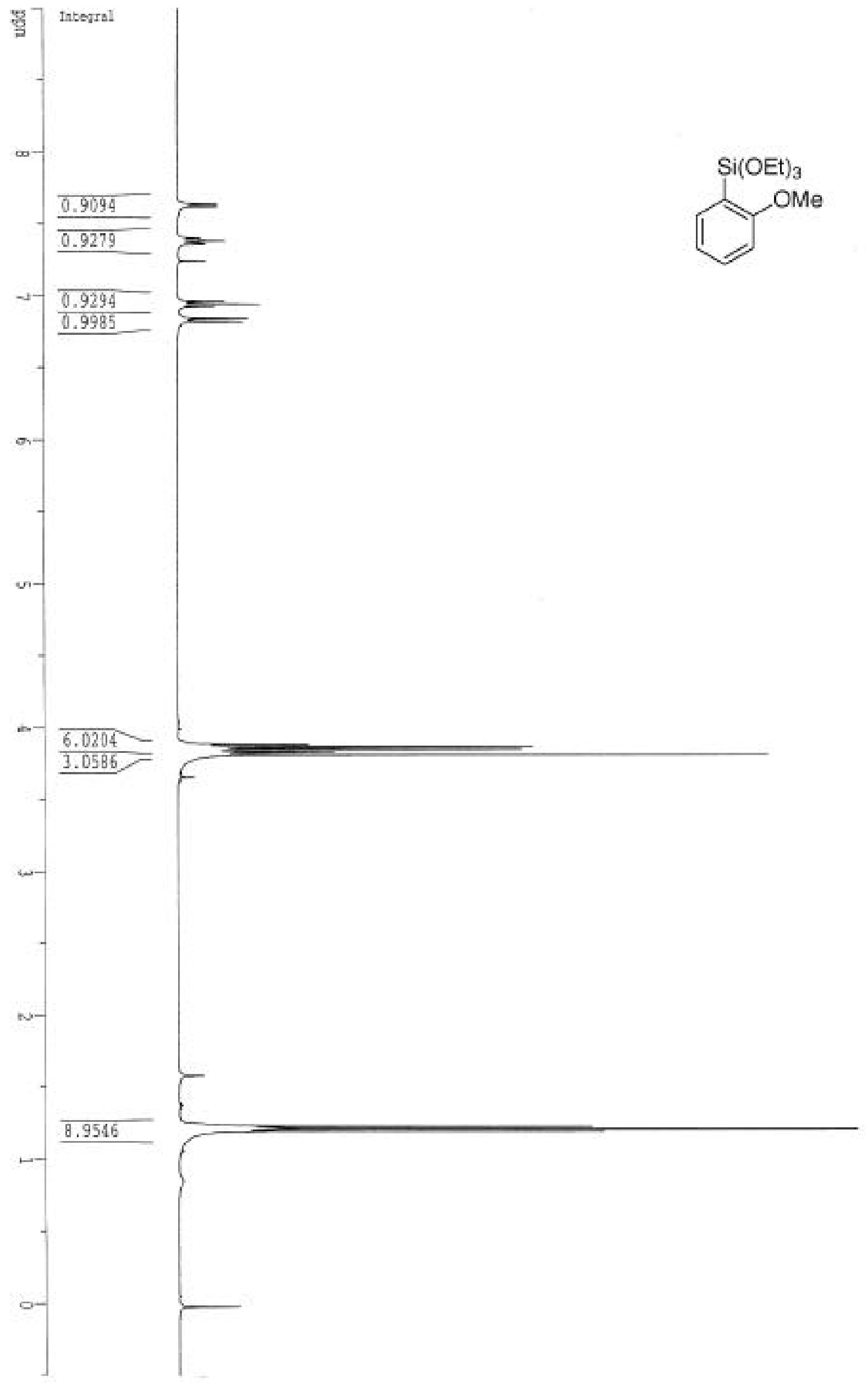




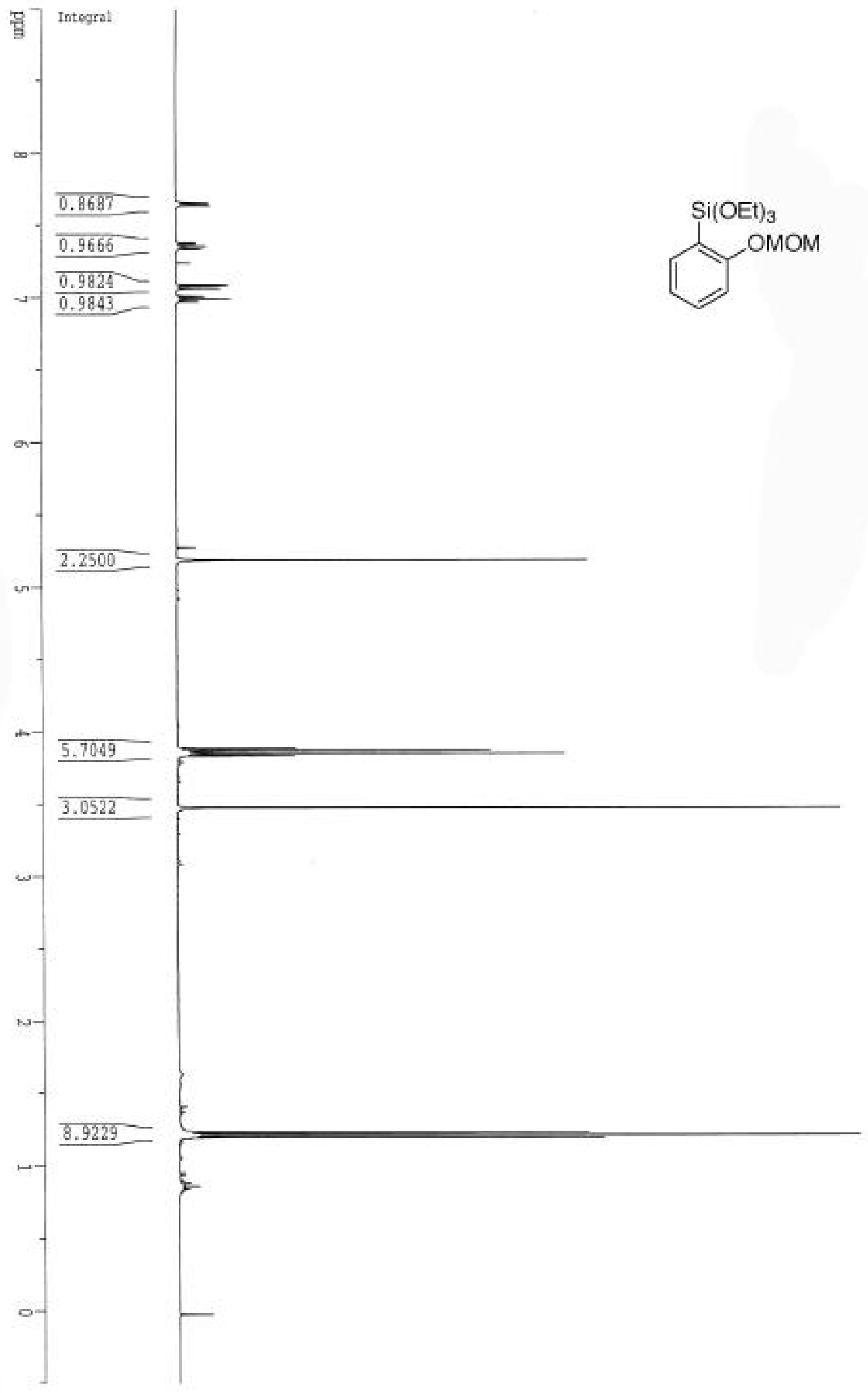




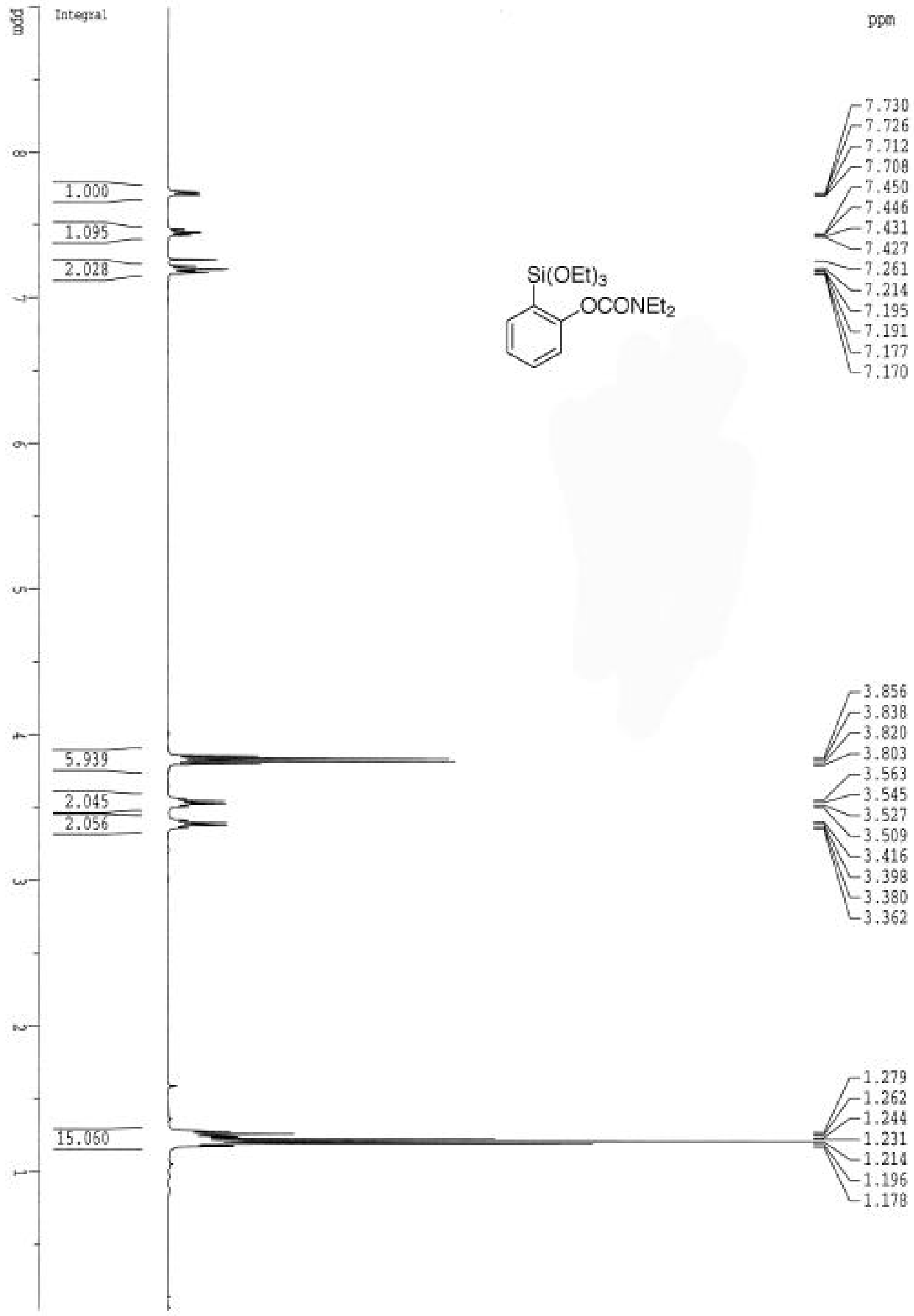




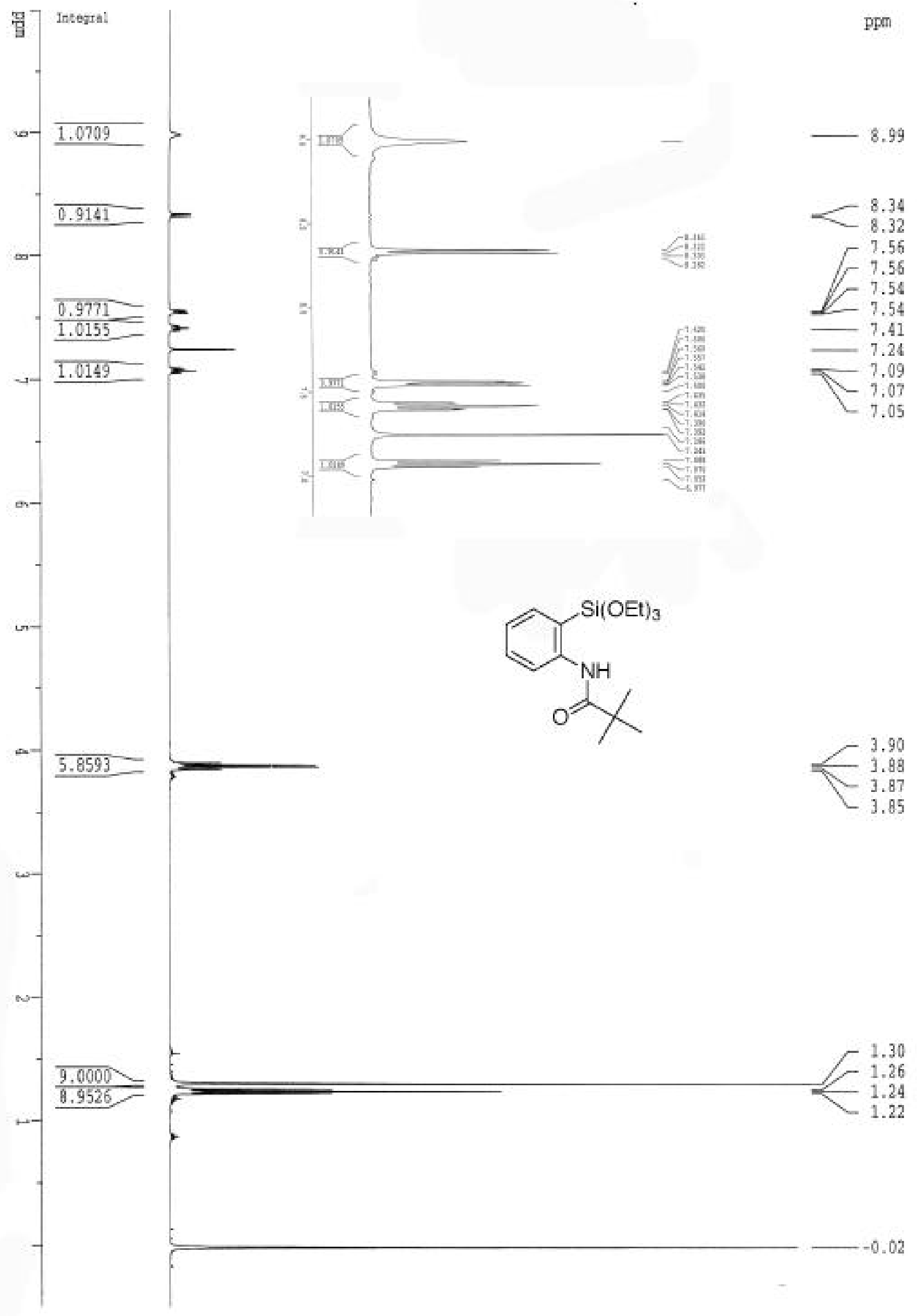




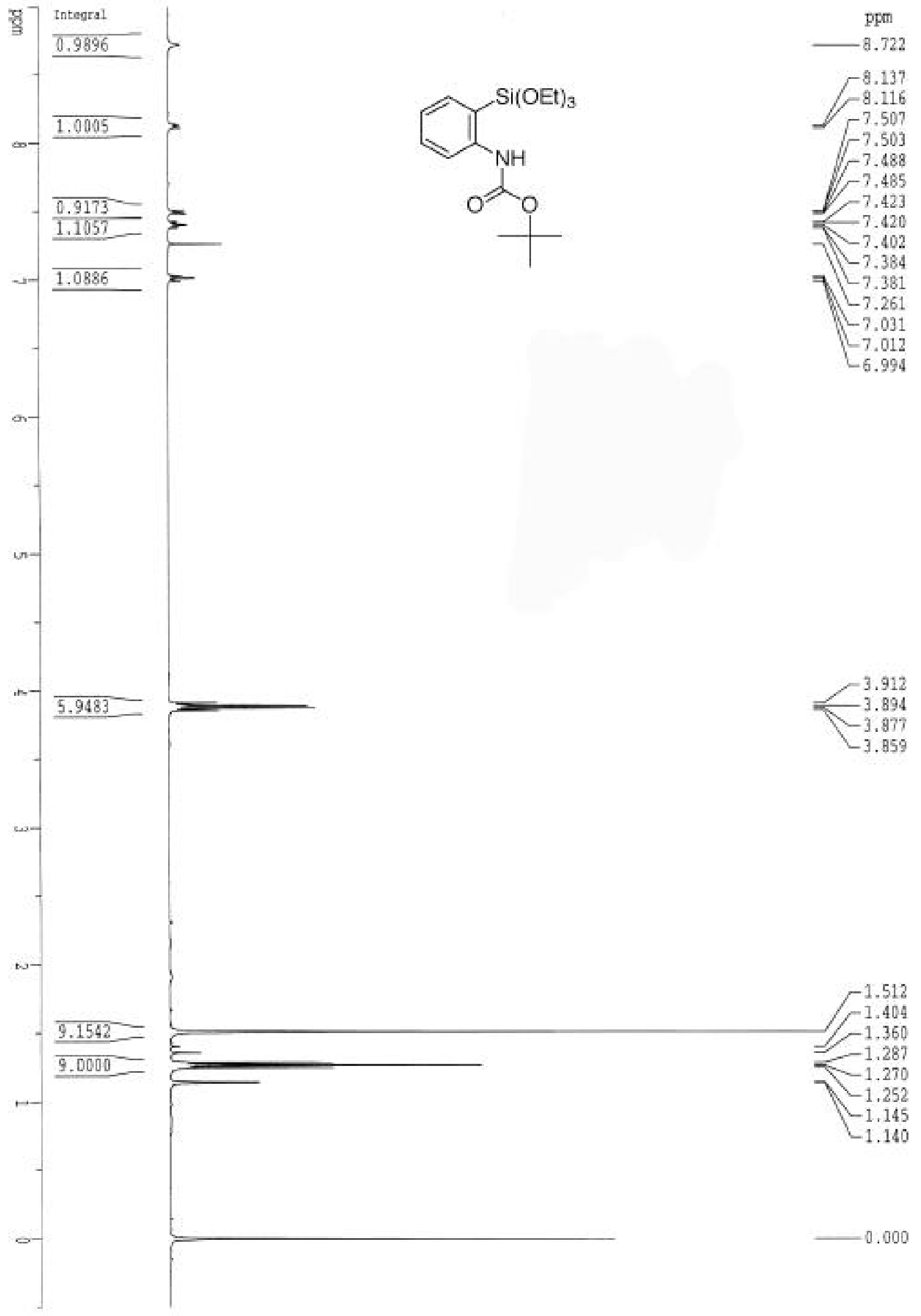




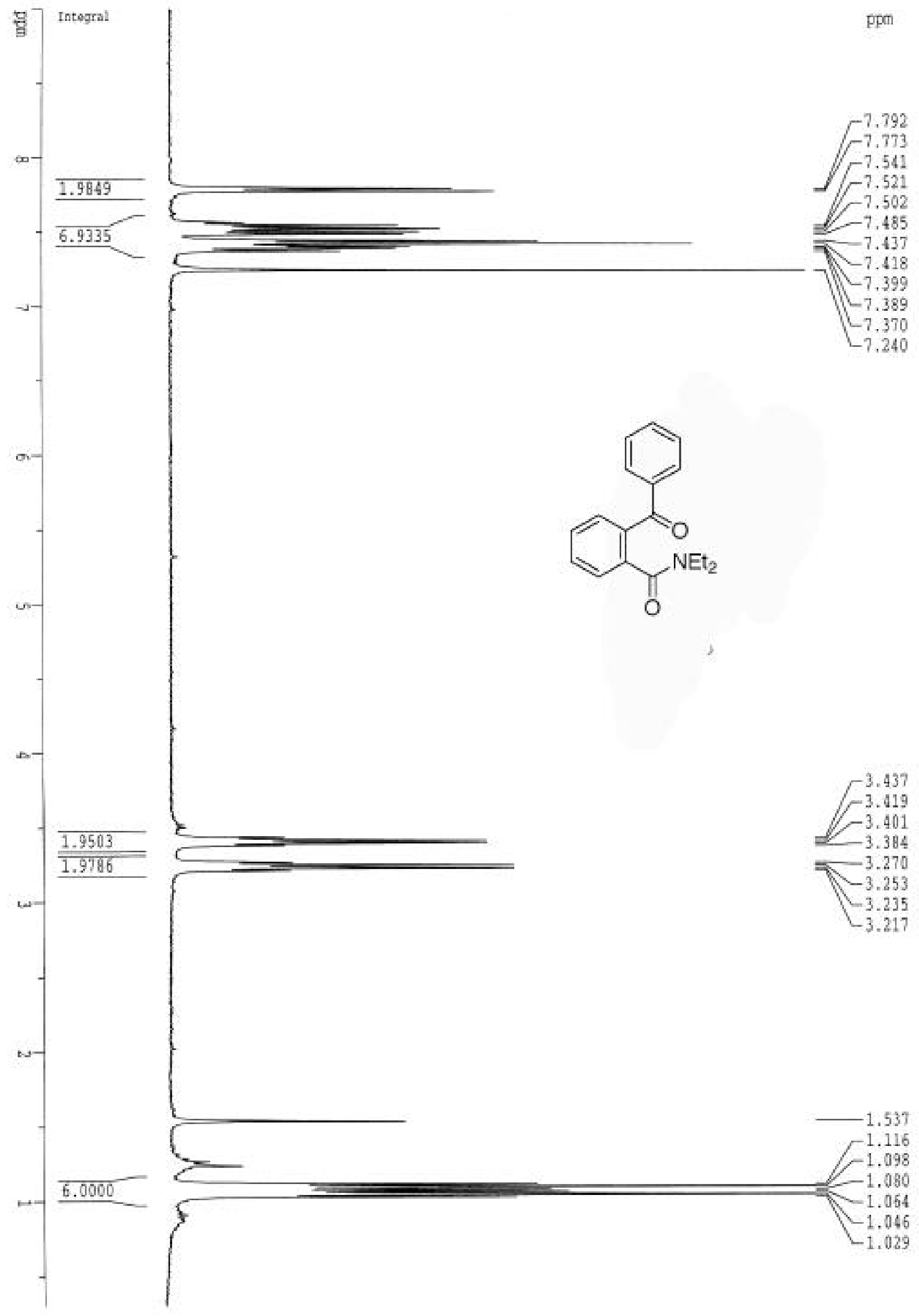




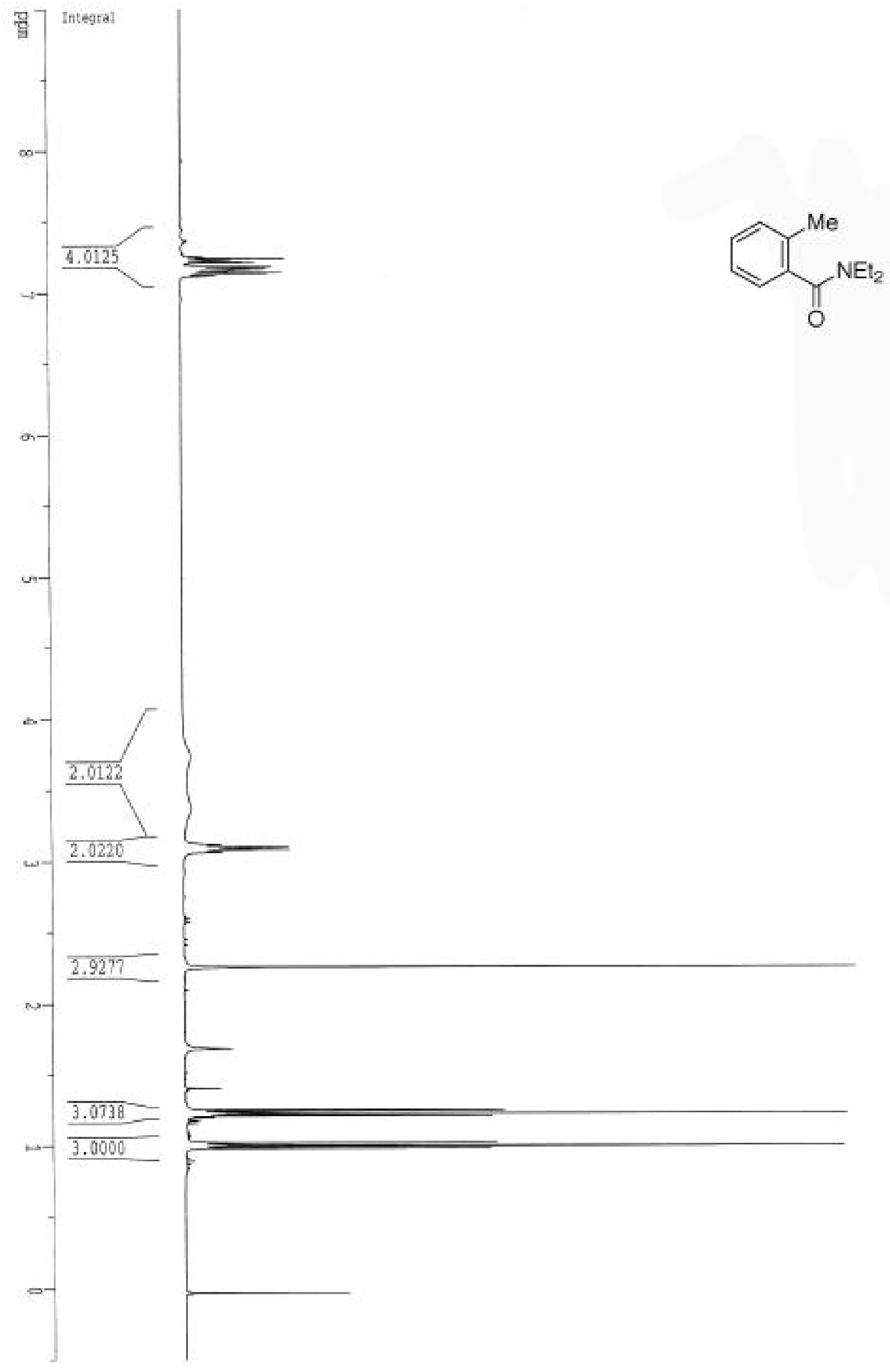




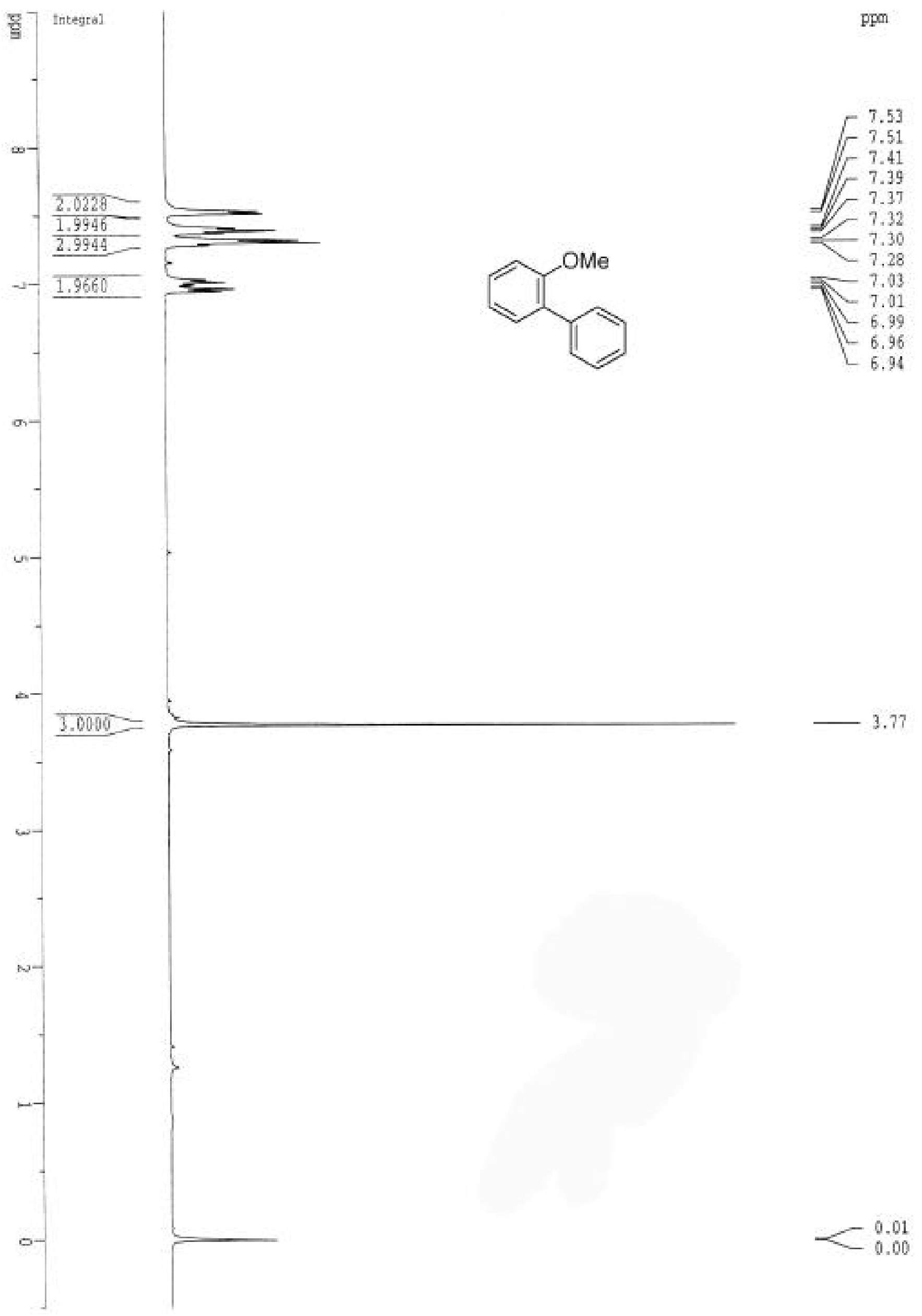




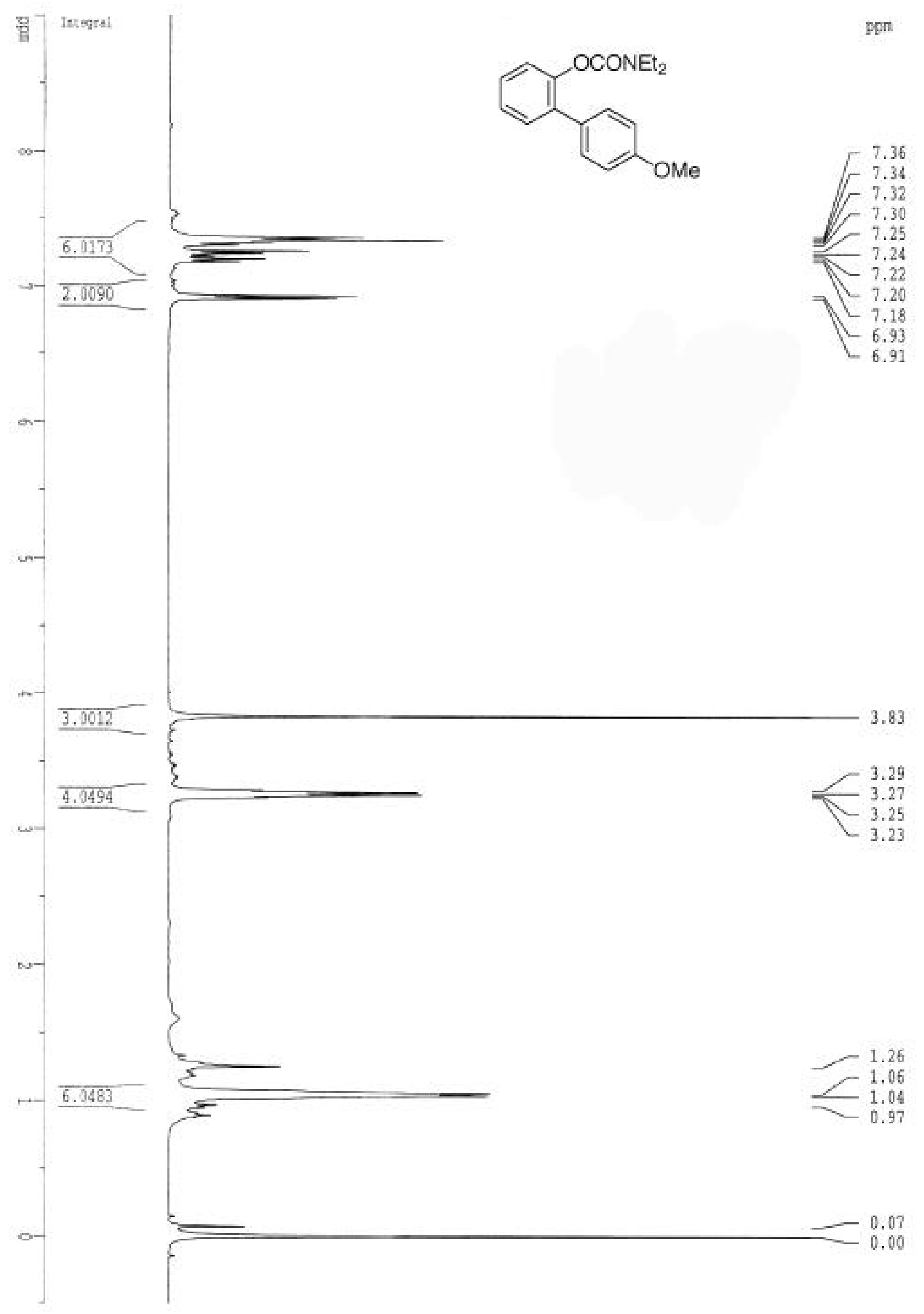




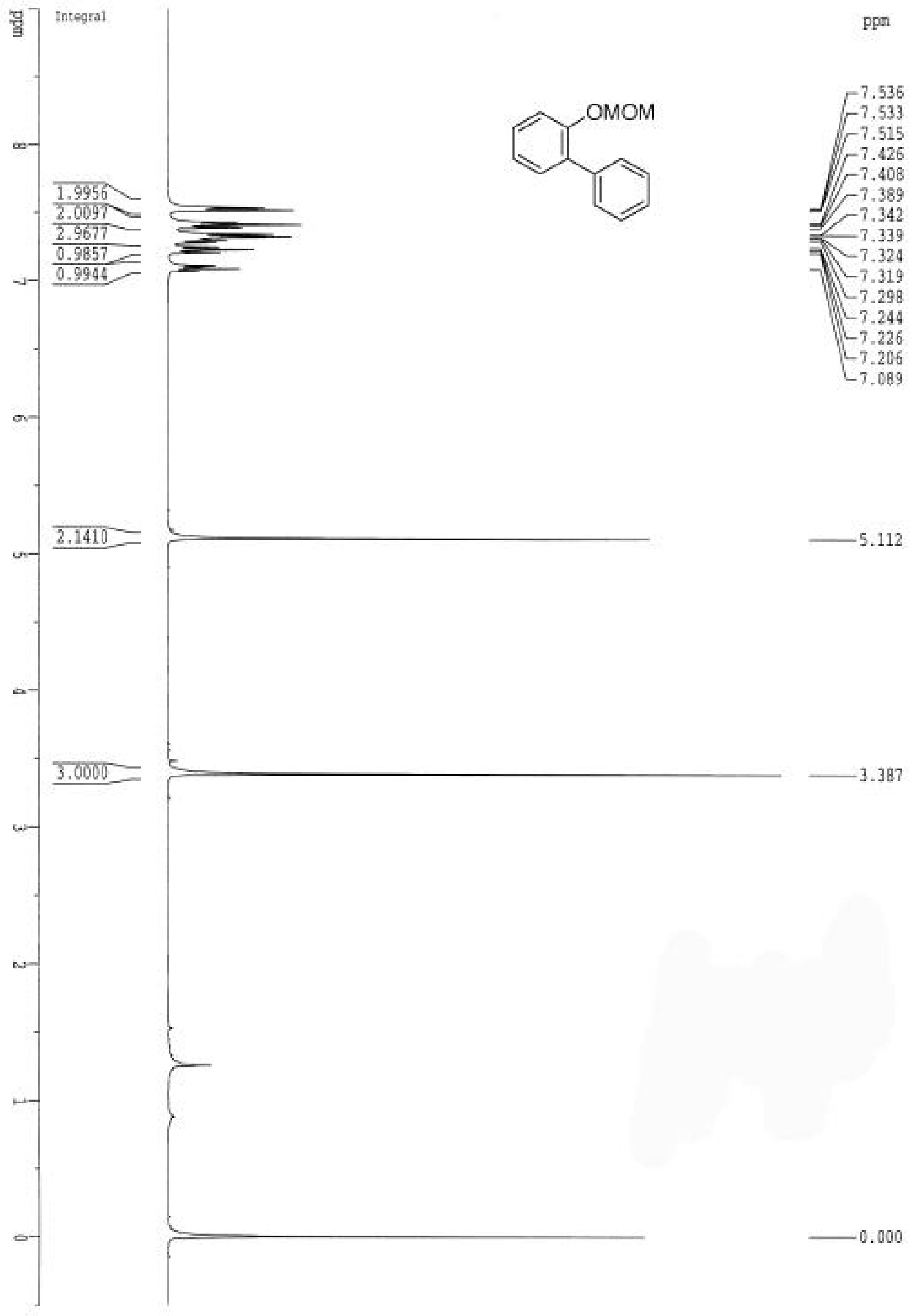




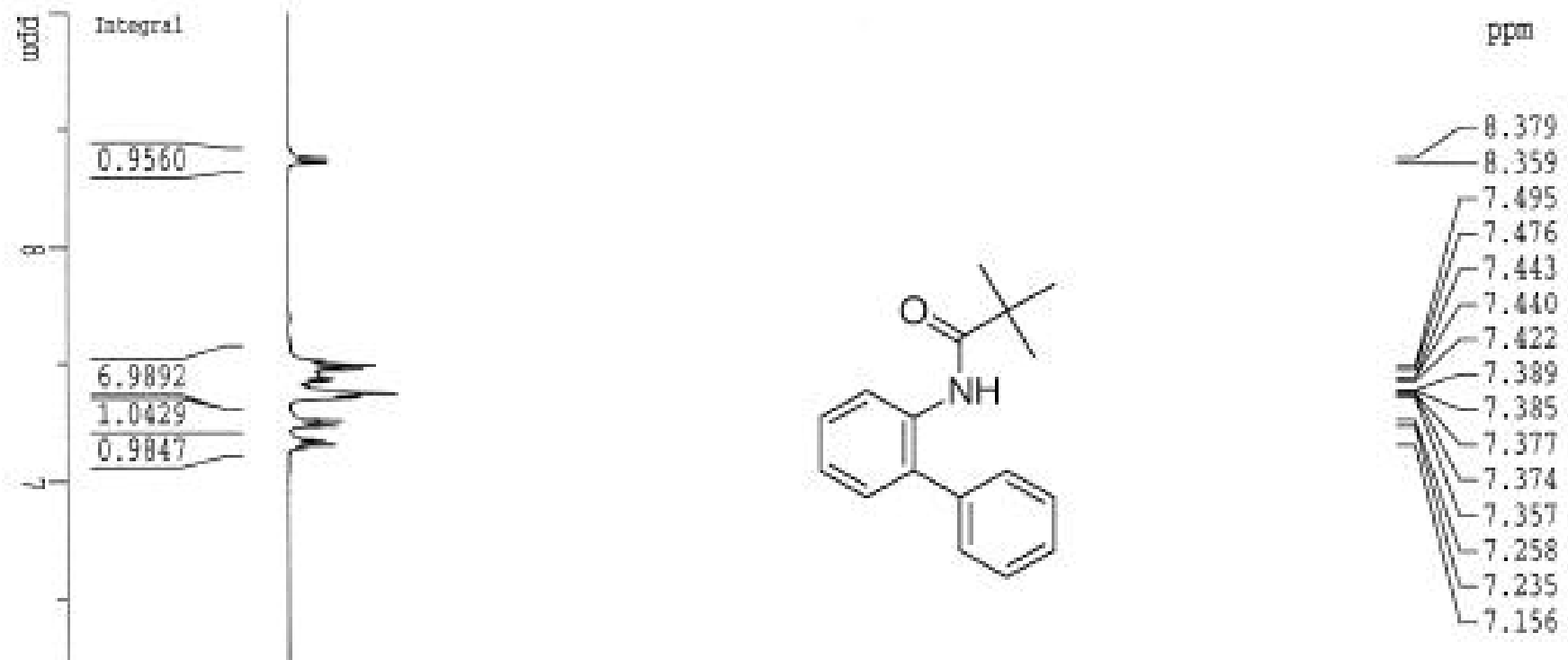




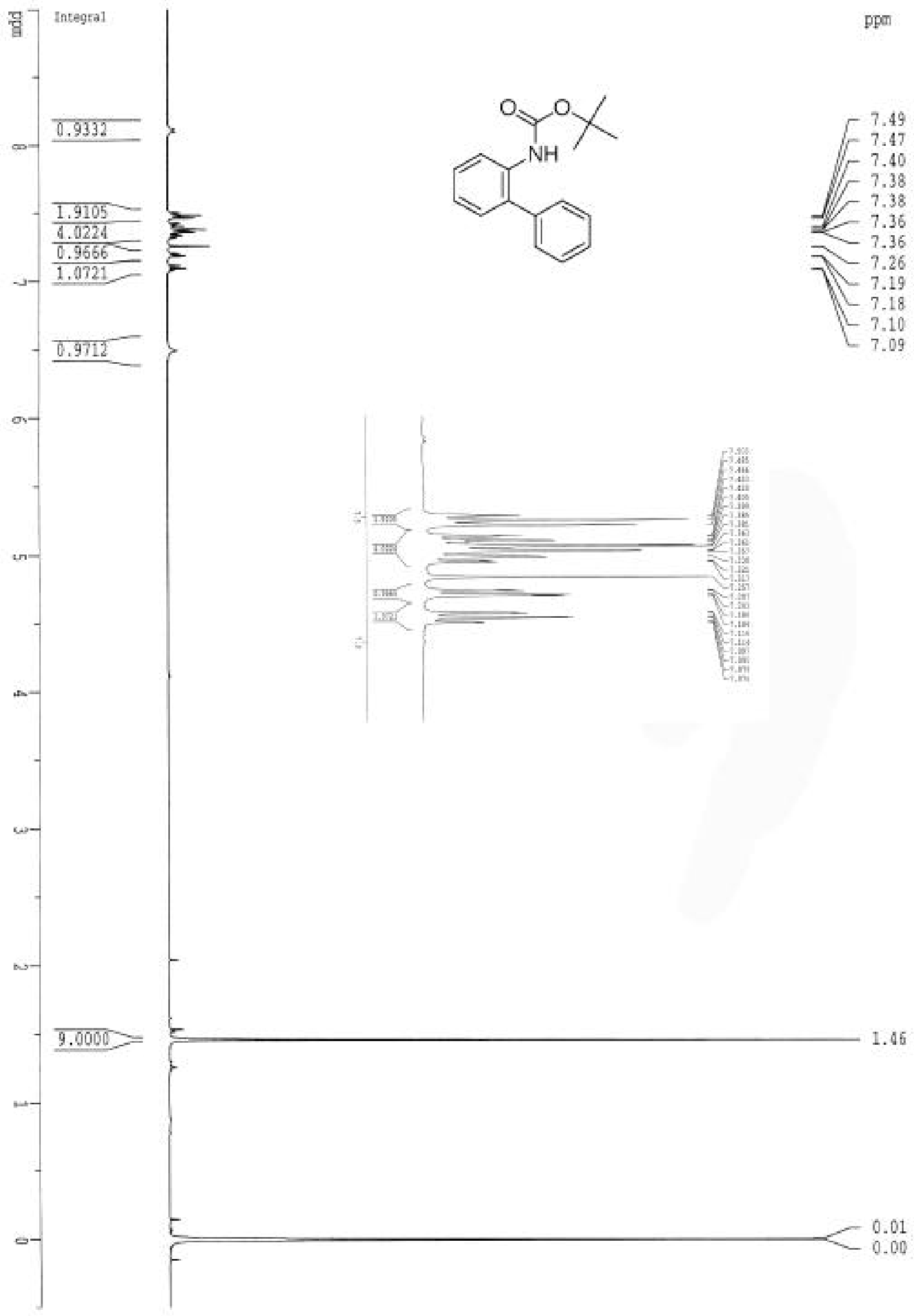




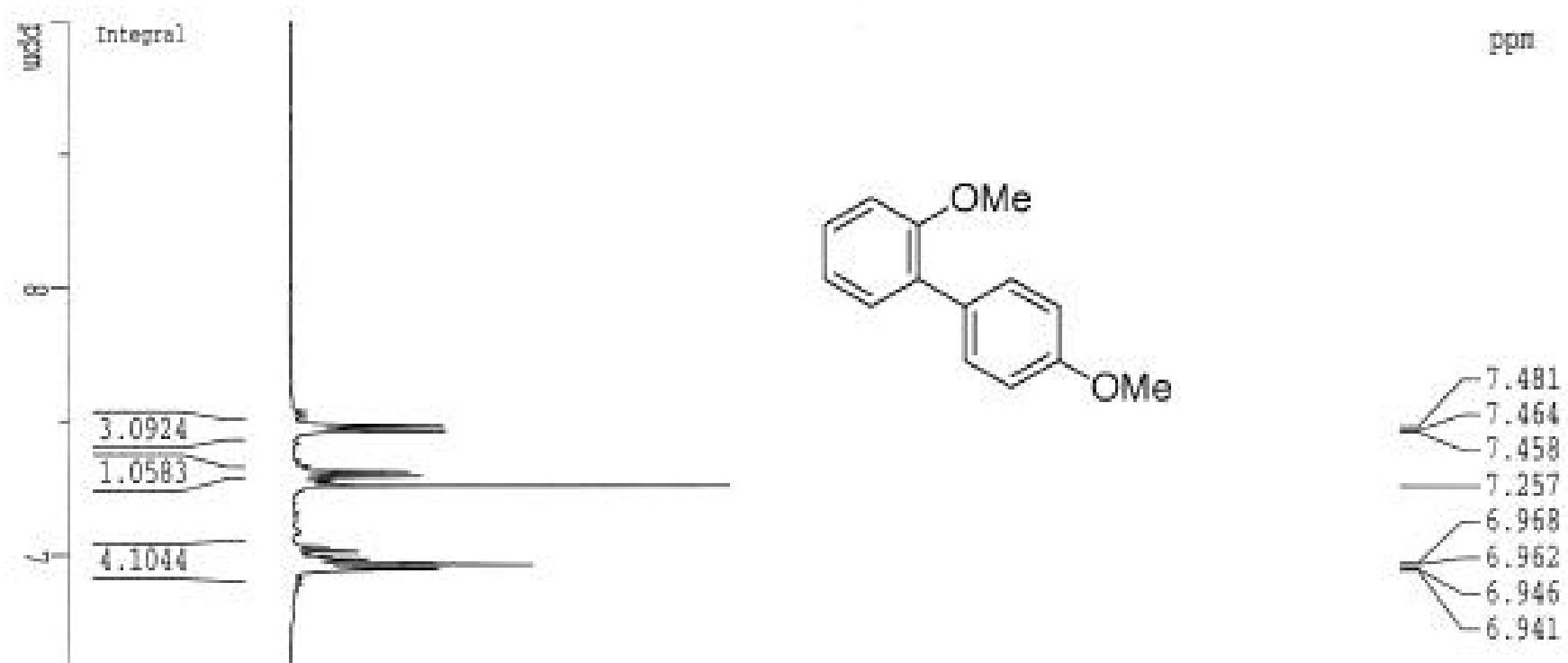




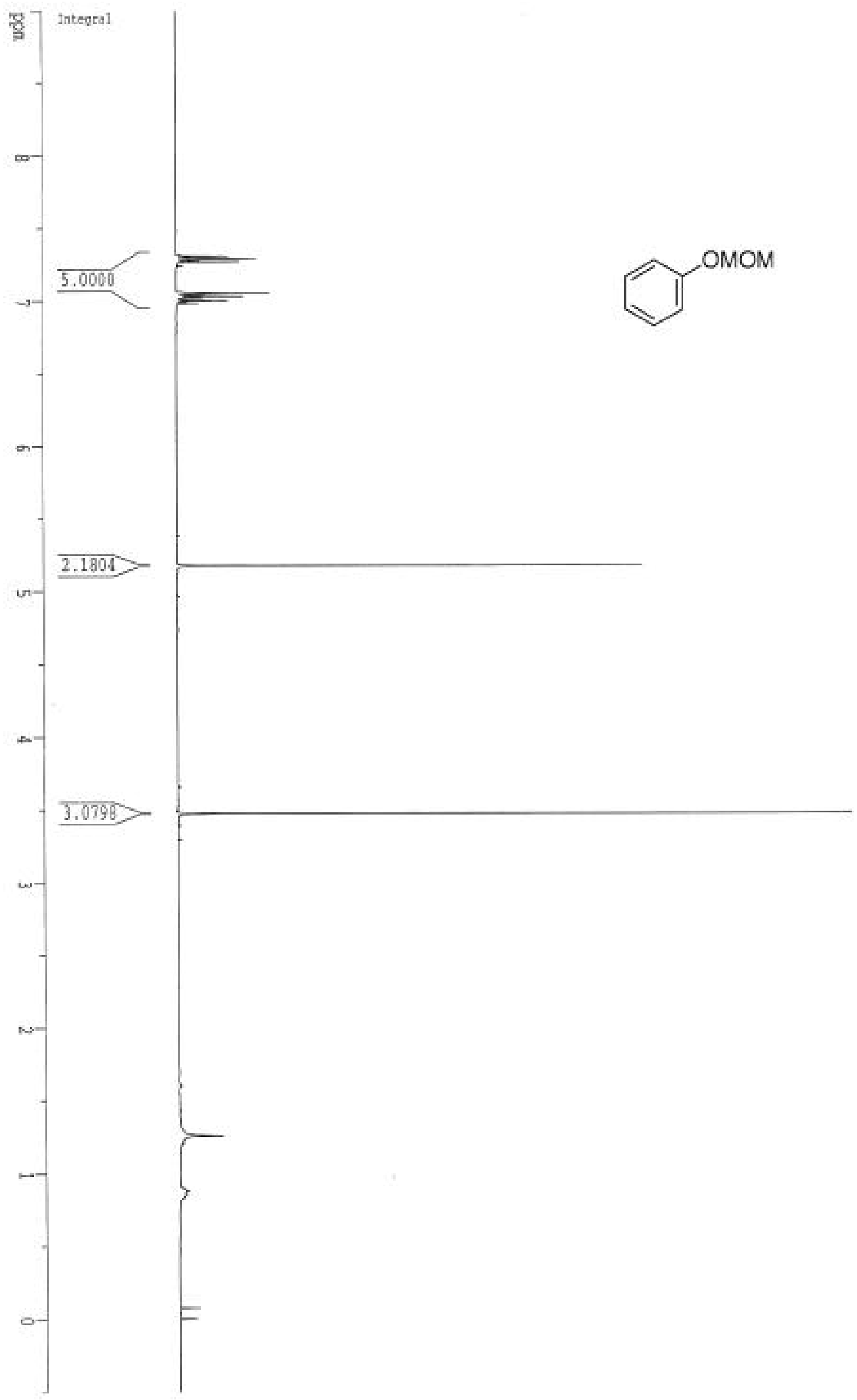




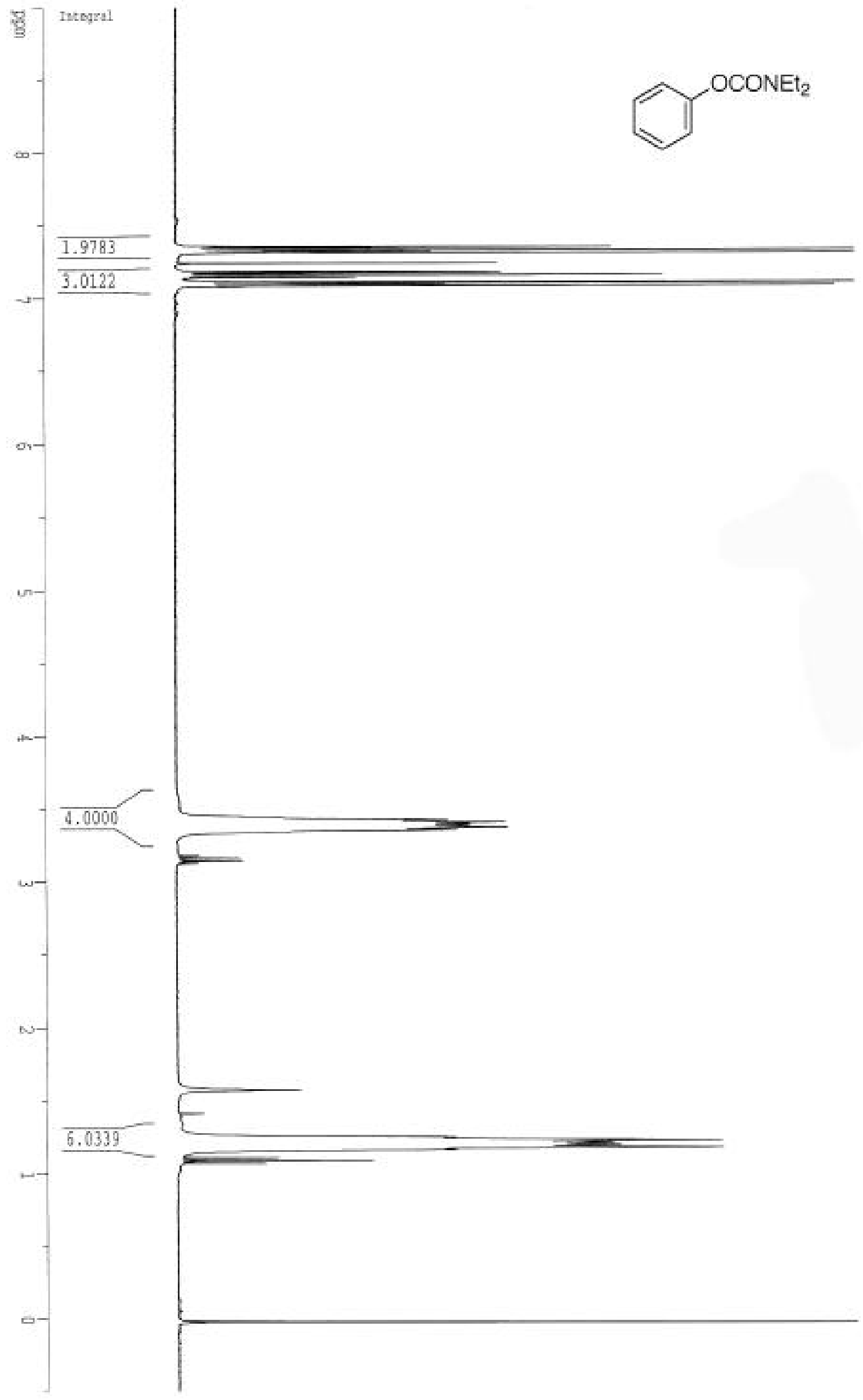




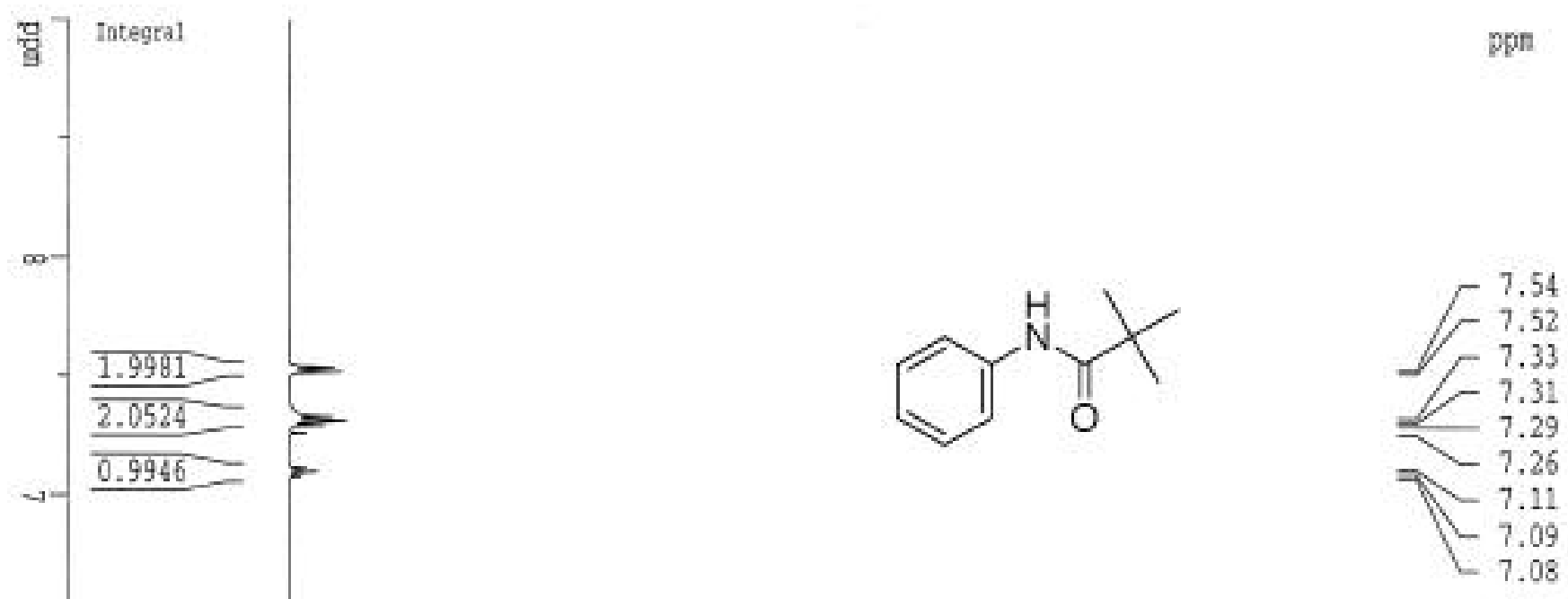




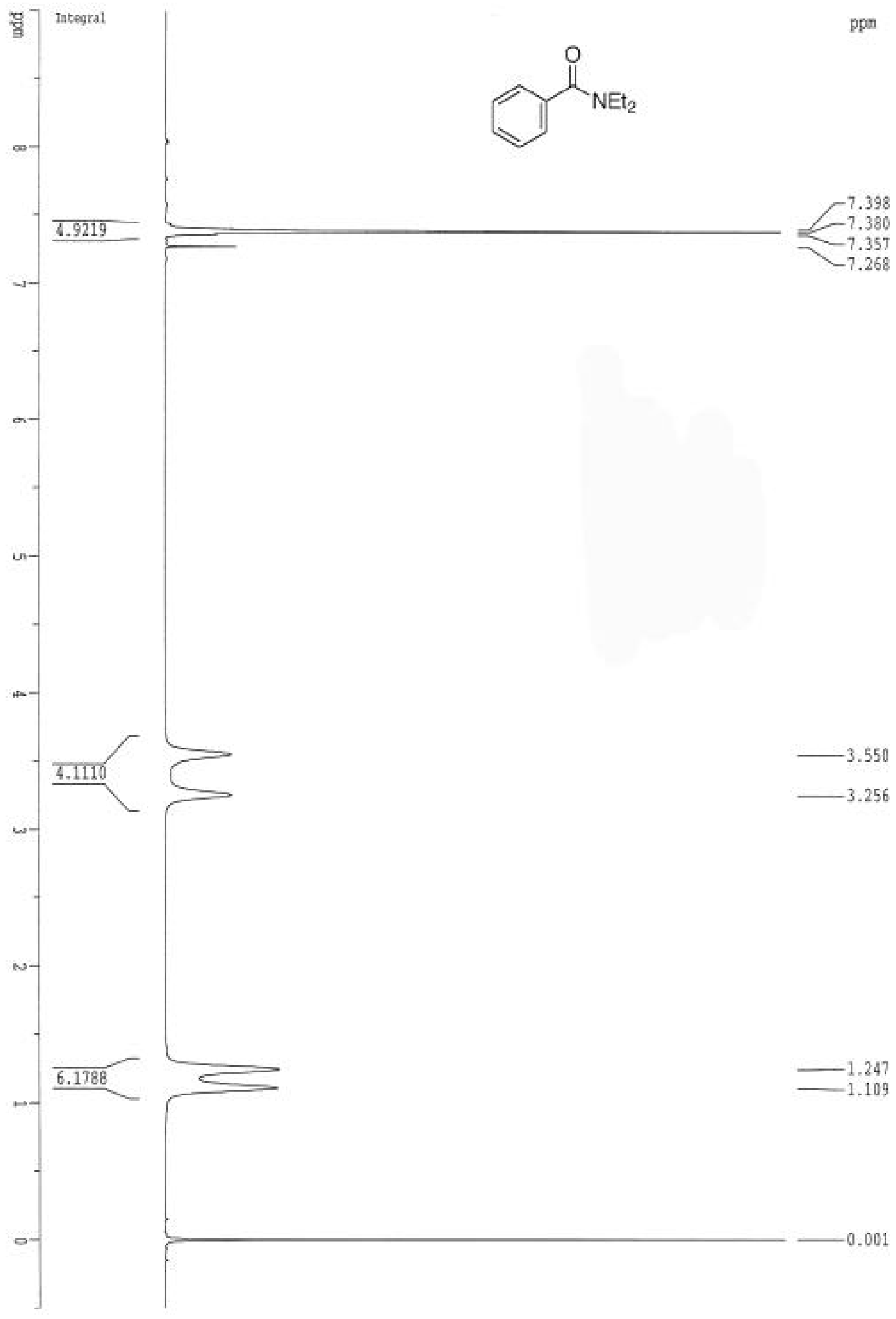




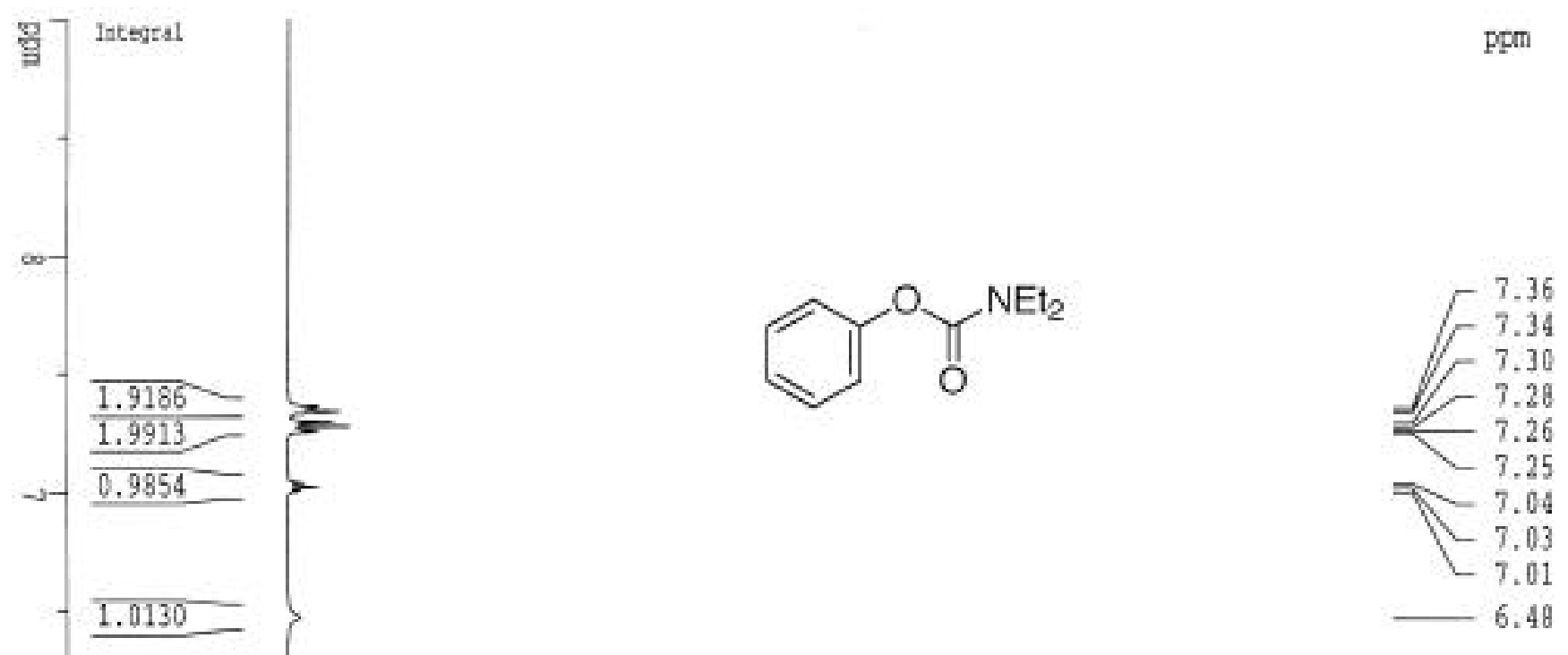

